\title{
A CONTROVÉRSIA DOS PNEUS, O PRINCÍPIO DA PREVENÇÃO E PRECAUÇAO E O DEVER DE SUSTENTABILIDADE
}

\author{
Marco Aurélio Ramos da Silva ${ }^{1}$
} Aline Casagrande ${ }^{2}$

\begin{abstract}
Resumo
$\mathrm{O}$ artigo trata de questões ambientais que envolvem o uso de pneumáticos e seu impacto no meio ambiente após seu uso, bem como técnicas para utilização sustentável minimizando danos ambientais. O principio da prevenção e da precaução como formas de prevenir a poluição destes no meio ambiente evitando danos a saúde, bem como soluções viáveis para sua correta destinação.
\end{abstract}

Palavras-chave: dano ambiental; pneus; sustentabilidade; princípio prevenção e precaução.

\section{INTRODUÇÃO}

Os pneus ${ }^{3}$ usados são em nosso mundo moderno um dos grandes agentes poluidores, e a preocupação com a sustentabilidade faz com que o homem não os ignore. Os avanços tecnológicos bem como as novas tecnologias andam em um ritmo acelerado, e a revolução no setor dos transportes faz com que não se ignore a necessidade do uso de pneus. Cada vez mais estamos dependentes dos automóveis, nosso transporte de carga no Brasil é na sua grande parte por meio rodoviário. A utilização dos pneus de borracha trouxe consigo a problemática do impacto ambiental, uma vez que a maior parte dos pneus descartados está abandonada em locais inadequados, causando grandes transtornos para a saúde e a qualidade de vida humana.

\footnotetext{
1 Acadêmico do $4^{\circ}$ semestre do Curso de Direito da Faculdade Palotina - FAPAS. E-mail: marcoaurelio_strt@hotmail.com.

${ }^{2}$ Professora da Faculdade Palotina - FAPAS - Santa Maria/RS; Advogada. Especialista em Direito Civil pela Universidade Federal de Santa Maria - UFSM. Mestranda em Direito pela Universidade de Santa Cruz do Sul - UNISC. Linha de Pesquisa: Políticas Públicas de Inclusão Social. Grupo de Estudos em Direito, Inovação e Propriedade Intelectual - GEDIPI. E-mail: casagrande.aline @ gmail.com.

3 - RESOLUÇÃO CONAMA n ${ }^{\circ}$ 258, de 26 de agosto de 1999.

Art. $2^{\circ}$ : Para os fins do disposto nesta Resolução, considera-se:

I - pneu ou pneumático: todo artefato inflável, constituído basicamente por borracha e materiais de reforço utilizados para rodagem em veículos automotores e bicicletas; (nova redação dada pela Resolução $\mathrm{n}^{\circ} 301 / 02$ )

II - pneu ou pneumático novo: aquele que nunca foi utilizado para rodagem sob qualquer forma, enquadrando-se, para efeito de importação, no código 4011 da Tarifa Externa Comum - TEC;

III - pneu ou pneumático reformado: todo pneumático que foi submetido a algum tipo de processo industrial com o fim específico de aumentar sua vida útil de rodagem em meios de transporte, tais como recapagem, recauchutagem ou remoldagem, enquadrando-se, para efeitos de importação, no código 4012.10 da Tarifa Externa Comum-TEC;

IV - pneu ou pneumático inservível: aquele que não mais se presta a processo de reforma que permita condição de rodagem adicional, conforme código 4012.20 da Tarifa Externa Comum - TEC.
} 


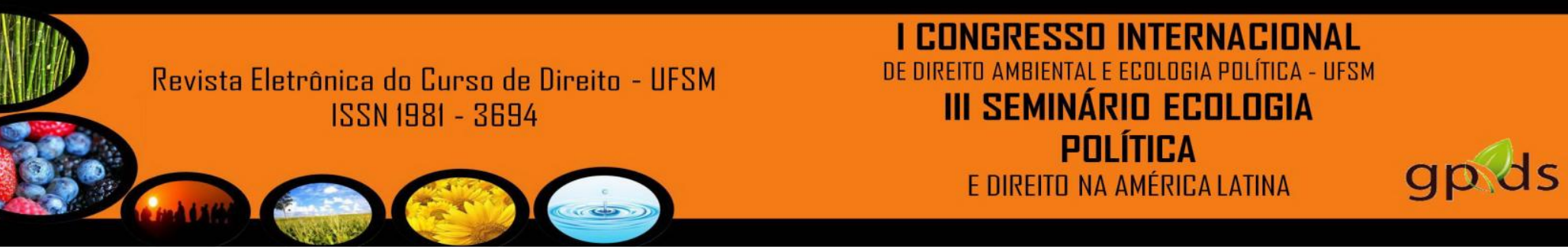

Temos tido grandes avanços no aspecto de legislação ambiental no Brasil, contudo ainda temos muita carência no aspecto correta distinção e reaproveitamento desses milhões de matéria prima. Para os pneus expostos a céu aberto ainda não existe um tempo definido para sua decomposição, que podem levar milhares de anos.

\section{Dano Ambiental causado pelo descarte de pneus usados}

O ser humano, que tem no art. $225^{4}$, meio ambiente como um bem difuso, não pode aceitar a degradação de lagos, rios, mares, bem como a proliferação de mosquitos devido ao grande acumulo de pneus velhos, que servem como morada de insetos e acumulo de água de chuva, causando inúmeras doenças, dengue e febre amarela, pois se constituem jogados na natureza um meio propício para sua proliferação de insetos, poluído o meio ambiente e causando um desequilíbrio ambiental.

Segundo o que determina o art. $14^{5}$ da LEI 6.938/81, o próprio texto coloca como figuras distintas dos danos causados ao meio ambiente e os danos causados a terceiros resultantes da agressão ao meio ambiente, temos nos pneus jogados no ambiente um perigo a saúde das pessoas bem como sua queima na natureza causa uma grande poluição que vem afetar em grandes cidades a uma gama enorme de pessoas.

\footnotetext{
${ }^{4}$ Art. 225 - Todos têm direito ao meio ambiente ecologicamente equilibrado, bem de uso comum do povo e essencial à sadia qualidade de vida, impondo-se ao Poder Público e à coletividade o dever de defendê-lo e preservá-lo para as presentes e futuras gerações.

V - controlar a produção, a comercialização e o emprego de técnicas, métodos e substâncias que comportem risco para a vida, a qualidade de vida e o meio ambiente;

$\S \mathbf{3}^{\mathbf{0}}$ - As condutas e atividades consideradas lesivas ao meio ambiente sujeitarão os infratores, pessoas físicas ou jurídicas, a sanções penais e administrativas, independentemente da obrigação de reparar os danos causados.

${ }^{5}$ Art 14 - Sem prejuízo das penalidades definidas pela legislação federal, estadual e municipal, o não cumprimento das medidas necessárias à preservação ou correção dos inconvenientes e danos causados pela degradação da qualidade ambiental sujeitará os transgressores:

I - à multa simples ou diária, nos valores correspondentes, no mínimo, a 10 (dez) e, no máximo, a 1.000 (mil) Obrigações Reajustáveis do Tesouro Nacional - ORTNs, agravada em casos de reincidência específica, conforme dispuser o regulamento, vedada a sua cobrança pela União se já tiver sido aplicada pelo Estado, Distrito Federal, Territórios ou pelos Municípios.

II - à perda ou restrição de incentivos e benefícios fiscais concedidos pelo Poder Público;

III - à perda ou suspensão de participação em linhas de financiamento em estabelecimentos oficiais de crédito;

IV - à suspensão de sua atividade.

$\S 1^{\circ}$ - Sem obstar a aplicação das penalidades previstas neste artigo, é o poluidor obrigado, independentemente da existência de culpa, a indenizar ou reparar os danos causados ao meio ambiente e a terceiros, afetados por sua atividade. O Ministério Público da União e dos Estados terá legitimidade para propor ação de responsabilidade civil e criminal, por danos causados ao meio ambiente.
} 
Temos uma grande demanda de pneus velhos, pois cada vez mais a indústria automobilística se expande sendo uma consumidora em potencial de pneus novos, os quais com 2 (dois) anos ou $60.000 \mathrm{Km}$ serão substituídos por novos, segundo próprio fabricante. Um pneu exposto ao céu aberto tem um tempo ainda indefinido quanto a sua decomposição, gerando um grave problema ambiental e de saúde pública. Segundo Rodrigues (2005, p.299) “pode-se inferir que toda poluição gera um dano ambiental”.

Somos seres consumistas e pouco ambientalistas, nos preocupamos com o meio ambiente, mas delegamos essa problemática aos ambientalistas. Atitudes simples de nosso dia à dia podem além de gerar economia, contribuir significativamente para prevenir e aumentar a vida útil dos pneus, reduzida pela metade por falta de calibragem, geometria, balanceamento de rodas, freadas bruscas sem necessária atitude.

Não é só o desenvolvimento não sustentável que causa a degradação ambiental. O consumo não sustentável também esta na origem de muitos males ambientais. Temos grandes avanços no aspecto legislação ambientais no Brasil, contudo ainda temos muita carência no aspecto correta destinação e reaproveitamento desses milhões de matéria prima descartada todos os dias.

Quinhentos milhões de automóveis foram licenciados no mundo entre 1950 e 2000, isso significa em pneumáticos essa soma acrescida no mínimo em 5 vezes esse valor. Cada automóvel leva consigo 5 pneus novos, um veículo trator atrelado a um semi-reboque de 4 eixos, desgasta diariamente aproximadamente 26 pneus diários. Precisamos de soluções viáveis para garantir sustentabilidade e meio ambiente sadio, entre elas podemos destacar o uso de pneus usados nas usinas de asfalto, coprocessamento em fornos de cimento, co-processamento e cimenteiras, coprocessamento na usina de xisto betuminoso, em fabricação de tijolos mais baratos resistentes a água, casas, pré-lajens, parquinhos, e no que e seu maior destino na atualidade, seu uso como matéria-prima, ou combustível, para fabricação de cimento.

Soluções viáveis para destruição e reaproveitamento de pneus usados passam pela indústria. O dano ambiental gerado pelos pneumáticos inservíveis e as perspectivas de reaproveitamento como matéria-prima, vem conservando as jazidas naturais de vários minérios, bem como de auxiliando para conservação de florestas e queima de combustíveis, haja vista que os pneus inservíveis são uma grande fonte de energia. As novas tecnologias estão a nossa volta e a criatividade da sociedade, fabricantes, 


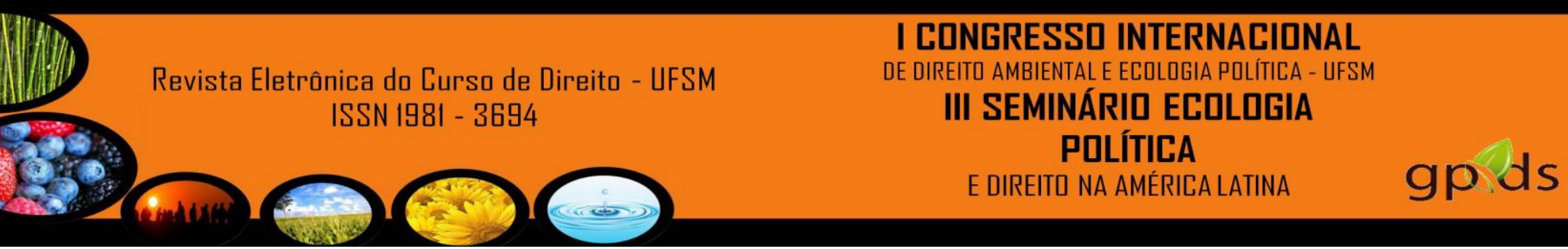

Sua relação custo benefício é bem mais vantajosa na manutenção do pavimento.

Processo que recicla os pneus diagonais é conhecido como laminação, de sua produção tem diversos produtos como passadeiras, saltos e solados de sapatos, colas e adesivos, rodos domésticos, tiras pra indústria de estofados etc.

Os pneus dispostos inadequadamente constituem passivo ambiental, que podem resultar em sério risco ao meio ambiente e à saúde pública. ${ }^{8}$ Segundo essa norma as empresas fabricantes e as importadoras de pneumáticos ficam obrigadas a coletar e dar destinação final, ambientalmente adequada, aos pneus inservíveis existentes no território nacional, na proporção definida na Resolução do CONAMA n ${ }^{\circ} 258$ que dispõe sobre os pneumáticos. Temos no Brasil legislação e norma específica sobre a questão de resíduos industriais.

\section{A Constituição Brasileira e o Princípio da Prevenção e Precaução: "A} Constituição Federal do Brasil tem um capitulo especial que dispõe sobre o Meio Ambiente: capítulo VI no Título VIII da Ordem Social". 9

A teoria econômica de que os custos sociais externos que acompanham o processo produtivo (o custo resultante de danos ambientais) devem ser internalizados, ao levar em conta os custos da produção e assumir os riscos do dano ao meio ambiente. Busca-se imputar ao poluidor no caso de pneumáticos o custo social da poluição por ele gerada. Não imputando somente aos produtos os danos causados sobre os bens e pessoas, mas também ao meio ambiente. $\mathrm{O}$ agente poluidor também é obrigado a

\footnotetext{
${ }^{8}$ Res. Conama 416/09 O CONSELHO NACIONAL DO MEIO AMBIENTE-CONAMA, no uso das atribuições que lhe são conferidas pelo art. 8o, inciso VII, da Lei no 6.938, de 31 de agosto de 1981, e tendo em vista o disposto em seu Regimento Interno, e Considerando a necessidade de disciplinar o gerenciamento dos pneus inservíveis;

Considerando que os pneus dispostos inadequadamente constituem passivo ambiental, que podem resultar em sério risco ao meio ambiente e à saúde pública;

Art. 1o Os fabricantes e os importadores de pneus novos, com peso unitário superior a 2,0 kg (dois quilos), ficam obrigados a coletar e dar destinação adequada aos pneus inservíveis existentes no território nacional, na proporção definida nesta Resolução.

$\S 1$ o Os distribuidores, os revendedores, os destinadores, os consumidores finais de pneus e o Poder Público deverão, em articulação com os fabricantes e importadores, implementar os procedimentos para a coleta dos pneus inservíveis existentes no País, previstos nesta Resolução.

§ 2o Para fins desta resolução, reforma de pneu não é considerada fabricação ou destinação adequada.

§ 3o A contratação de empresa para coleta de pneus pelo fabricante ou importador não os eximirá da responsabilidade pelo cumprimento das obrigações previstas no caput deste artigo.

9 Art. 225 - Todos têm direito ao meio ambiente ecologicamente equilibrado, bem de uso comum do povo e essencial à sadia qualidade de vida, impondo-se ao Poder Público e à coletividade o dever de defendê-lo e preservá-lo para as presentes e futuras gerações.
} 


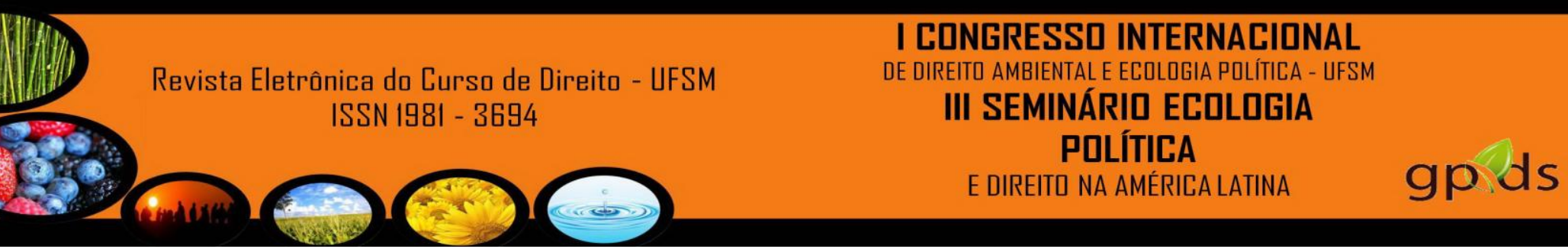

corrigir ou recuperar o ambiente, dos danos causados, suportando os encargos resultantes de sua ação poluente. No art. $143^{\circ}$ da Lei $6.938 / 81$, o poluidor é obrigado independente da existência de culpa, a indenizar ou reparar os danos causados ao meio ambiente e a terceiros, afetados por sua atividade. ${ }^{10}$

Considerando que pneus são bens insubstituíveis, essências ao desenvolvimento de quaisquer pais, a única possibilidade de aplicar o princípio da não geração de impactos nesse contexto é a correta aplicação por parte dos consumidores que também tem sua responsabilidade ambiental sobre o descarte de seus pneus usados.

Busca-se uma sadia qualidade de vida do homem, mas o progresso e os avanços tecnológicos nos levam a um dilema, desenvolver sustentavelmente. Temos nesse aspecto dois princípios de extrema importância que devem ser agregados na problemática dos pneumáticos, o princípio da prevenção o princípio da precaução. $\mathrm{O}$ principio da prevenção se refere ao perigo concreto dos pneumáticos, porém o da prevenção é dirigido a um perigo abstrato.

O princípio da prevenção busca medidas preventivas com objetivo de evitar danos irreversíveis ou de difícil reparação, como exemplo aterros feitos com pneus. Nesse contexto conhece-se o risco e tomam-se medidas para evitá-lo. Busca-se inibir o risco de dano, no caso os pneumáticos e as consequências de seu descarte no meio ambiente.

No princípio da precaução, não se tem certeza sobre o que acontecerá, então se decide por uma cautela antecipada, diante de um possível risco ou perigo. Entendido com norteador das avaliações e decisões desses tipos de problemas que envolvem riscos para saúde e para o meio ambiente.

Temos possibilidades de práticas sustentáveis a partir da reutilização da matéria prima dos pneus.

\footnotetext{
${ }^{10}$ Art 14 - Sem prejuízo das penalidades definidas pela legislação federal, estadual e municipal, o não cumprimento das medidas necessárias à preservação ou correção dos inconvenientes e danos causados pela degradação da qualidade ambiental sujeitará os transgressores:

I - à multa simples ou diária, nos valores correspondentes, no mínimo, a 10 (dez) e, no máximo, a 1.000 (mil) Obrigações Reajustáveis do Tesouro Nacional - ORTNs, agravada em casos de reincidência específica, conforme dispuser o regulamento, vedada a sua cobrança pela União se já tiver sido aplicada pelo Estado, Distrito Federal, Territórios ou pelos Municípios.

II - à perda ou restrição de incentivos e benefícios fiscais concedidos pelo Poder Público;

III - à perda ou suspensão de participação em linhas de financiamento em estabelecimentos oficiais de crédito;

IV - à suspensão de sua atividade.
} 
Segundo Freitas (2011, p.51), conceito de sustentabilidade: é o principio constitucional que determina independente de regulamentação legal, com eficácia direta e imediata, a responsabilidade do Estado e da sociedade pela concretização solidária do desenvolvimento material e imaterial, socialmente inclusivo, durável e equânime, ambientalmente limpo, inovador, ético e eficiente, no intuito de assegurar, preferencialmente de modo preventivo e precavido, no presente e no futuro, o direito ao bem-estar físico, psíquico, espiritual, em consonância homeostática com o bem de todos.

A prática de um desenvolvimento sustentável, usando como a matéria prima os pneus usados, começa em reutilizar primeiramente no processo de recapagem, que absorveria boa parte de pneus ainda em condições de rodagem. Com o advento do desenvolvimento da indústria da reciclagem e de novas técnicas de pesquisas, podemos aproximar-se de um aproveitamento ainda mais específico e lucrativo, aliando desenvolvimento como o crescimento de novas tecnologias complexas voltadas para aliar os pneumáticos inservíveis com o meio ambiente e o homem visando a sustentabilidade.

Estamos em uma sociedade complexa, dentro de conceitos que visem a sustentabilidade e o desenvolvimentos temos também que preventivamente adotarmos atitudes simples de evitar o desgaste prematuro de pneus, entre os quais temos uma correta calibragem, geometria, um revisão na suspensão dos veículos, bem como balanceamento de rodas, contribuiremos para aumentar a vida útil dos pneus. Assim como também o Poder Público deve fiscalizar e evitar o ingresso de quantias adicionais de resíduos em terras brasileiras, tais como pneus usados, ou de curta duração como reformados, contudo já dispomos de legislação bem ampla e direta sobre o assunto, limitando-se o ingresso de pneus reformados apenas do MERCOSUL.

Como forma de minimizar a produção desses resíduos, o Dec. Federal 6.514, de 22.07.2008 ${ }^{11}$, que dispõe sobre as infrações e sanções administrativas ao meio ambiente, impõe uma multa de $\mathrm{R} \$ 400,00$ (quatrocentos reais) por unidade àquele que importar pneus usado ou reformado, bem como àquele que comercializar transportar, guardar ou manter em depósito pneus usado ou reformado, importado nessas condições.

\footnotetext{
${ }^{11}$ Art. 70. Importar pneu usado ou reformado em desacordo com a legislação: Multa de $\mathrm{R} \$ 400,00$ (quatrocentos reais), por unidade.

$\S 1^{\mathrm{o}}$ Incorre na mesma multa quem comercializa, transporta, armazena, guarda ou mantém em depósito pneu usado ou reformado, importado nessas condições.
} 
Neste mesmo decreto, inseriu-se o $§ 2^{\underline{0}}$ que dispõe sobre a importação de determinados pneumáticos reformados, procedentes de Estados-Partes do MERCOSUL. ${ }^{12}$ Para reduzir o volume de pneus inservíveis deve prevalecer a reutilização, reciclagem, recuperação energética e descarte de resíduos. O Brasil ocupa o $2^{\circ}$ lugar no ranking mundial de recauchutagem de pneus. A recauchutagem, seguindo as recomendações das normas para atividade, adiciona novas camadas de borracha nos pneus velhos, aumentando, desta forma, a vida útil do pneu em 100\% e proporcionando uma economia de cerca de $80 \%$ de energia e matéria-prima em relação à produção de pneus novos. $^{13}$

A expressão do princípio da prevenção, segundo a qual as agressões previsíveis ao meio ambiente devem ser antecipadas e evitadas, uma vez que a recuperação dos recursos naturais pode ser muito onerosa, incompleta as muitas vezes até impossível.

Toda proibição de pneus reformados contribui com o meio ambiente como uma medida necessária a proteção a vida e da saúde humana, animal e vegetal. Devemos ter em mente sempre o banimento de pneus inservíveis do meio ambiente. Temos a Res. $\mathrm{N}^{\circ}$ 452, de 02 de Julho de 2012, que dispõe sobre os procedimentos de controle da importação de resíduos, conforme as normas adotadas pela Convenção da Basiléia sobre o Controle de Movimentos Transfronteiriços de Resíduos Perigosos e seu Depósito. Temos visto a entrada de pneus chineses no Brasil, mesmo novos possui uma vida útil bem menor, contudo pelo preço atrativo atrai muitos consumidores, mesmo sabendo de seu desgaste prematuro e sua breve vida útil, se constituído em pouco tempo também mais um resíduo sólido no meio ambiente.

No Brasil a produção anual declarada e da ordem de quarenta milhões de unidades, e seu descarte estimado de vinte cinco milhões de pneus. ${ }^{14}$ Só no Brasil são produzidos cerca de 40 milhões de pneus por ano e quase metade dessa produção é descartada nesse período, ${ }^{15} \mathrm{em}$ locais impróprios.

$12 \S 2^{\frac{0}{}}$ Ficam isentas do pagamento da multa a que se refere este artigo as importações de pneumáticos reformados classificados nas NCM 4012.1100, 4012.1200, 4012.1300 e 4012.1900, procedentes dos Estados Partes do MERCOSUL, ao amparo do Acordo de Complementação Econômica n⿳o 18

${ }^{13}$ Fonte: Boletim Informativo da Bolsa de Reciclagem Sistema FIEP Ano I - N.mero 3 - JUL/AGO 2001

${ }^{14}$ Dados fornecidos pela Associação Brasileira de Revendedores de Pneus - ABRAPNEUS, 2000.

${ }^{15}$ Fonte: Boletim Informativo da Bolsa de Reciclagem Sistema FIEP Ano I - N.mero 3 - JUL/AGO 2001 



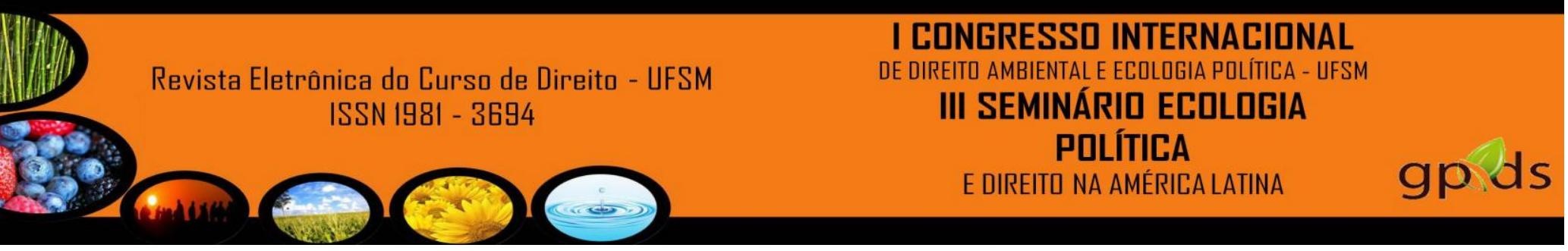

adotadas pela Convenção de Basiléia sobre o controle o controle de Movimentos Transfronteiriços de Resíduos Perigosos e seu Depósito.

Brasil, Resolução CONAMA n ${ }^{\circ}$ 264, de 26 de agosto de 1999. Licenciamento de fornos rotativos de produção de clínquer, para atividades de co-processamento de resíduos.

Brasil, Resolução CONAMA n 416, de 01 de outubro de 2009. Que disciplina a obrigação de destinação ambientalmente adequada de pneus inservíveis pelas empresas fabricantes e importadoras de pneus.

Brasil, Resolução CONAMA $n^{\circ} 452$, de 02 de julho de 2012. Dispõe sobre os procedimentos de controle da importação de resíduos, conforme as normas adotadas pela Convenção da Basiléia sobre o Controle de Movimentos Transfronteiriços de Resíduos Perigosos e seu Depósito.

Material da Internet:

$<$ http://www.pneusfacil.com.br/info/passo_de_remold.php $>$ Acesso em 28 ago.2012. $<\underline{\text { http://ambientes.ambientebrasil.com.br/residuos/reciclagem/reciclagem_de_pneus. }}$ $\underline{\mathrm{html}}>$ Acesso em 28 ago.2012. $\langle$ http://abrapneus.com.br/ > Acesso em 28 ago.2012. <http://www.anip.com.br/ > Acesso em 28 ago.2012. 